\title{
Some Studies on the Design Analysis and Fabrication of Wheat Cutting Machine
}

\author{
Roshan Raman', Gaurav Sharma', Akshay Kumar ${ }^{\dagger}$ and Manjeet Yadav $^{\dagger}$ \\ ${ }^{\dagger}$ Department of Mechanical Engineering, The North-Cap University, Sector 23A, Gurugram-122017, India \\ Received 01 March 2019, Accepted 01 May 2019, Available online 02 May 2019, Vol.9, No.3 (May/June 2019)
}

\begin{abstract}
In this study, collecting of wheat utilizing crop shaper was evaluated. Results demonstrated that the field limit of yield express was 2.44 occasions higher than the manual activity. The work prerequisite was 32.74 and $149.25 \mathrm{man}$-hr/ha for harvest shaper and manual activity, individually. If there should arise an occurrence of wheat, the field limit of product shaper was 2.23 occasions more noteworthy than manual reaping and work contribution was 23.20 and $115.74 \mathrm{man}-\mathrm{hr} / \mathrm{ha}$ for yield shaper and manual task, separately. It is expected by the use of this harvesting machine the farmers will be benefiting in terms of money as well as the physical task will be reduced significantly. Overall the cost of this manufactured machine was approx. 6000 INR.
\end{abstract}

Keywords: Wheat harvesting machine, shaper, cutter, harvesting.

\section{Introduction}

Reaping of yields in India is as yet done utilizing human work. Nonetheless, in a few parts of the nation, the reaping of wheat is done utilizing motor power. Wheat is the two most imperative staple nourishments for the general population of the Asian nations. Collecting is one of the significant field tasks for nourishment grain trims and devours as much as 20 $30 \%$ of difficult work prerequisite. The reaping process starts when the yield is physiologically developed, to get the most extreme recuperation of grains. Collecting ought to be done at a proper stage to limit misfortunes and to build the yield. Manual collecting of field crops is viewed as a work concentrated activity and takes from slicing to package making around 185-340 man-h/ha for paddy or wheat crops and 170-200 man-h/ha for paddy trim. As of late, different minimal effort collectors and Chinese brush cutters were entered in India for wheat gathering task. In eastern parts of the nation, particularly in Bihar, a large portion of the agriculturists are asset poor with little land property. The huge collecting machines like the consolidate collector are neither available to this livestock farmer nor for all intents and purposes practical because of little nor divided grounds. Hence, the fundamental goal of this examination was to assess the execution of product shaper reasonable for a gathering of both wheat and rice for little and peripheral agriculturists. India comes next in the ranch item over the globe. In

*Corresponding author's ORCID ID: 0000000285674412 https://doi.org/10.14741/ijcet/v.9.3.2 this way, trim cutting is the profited factor in the cultivating. For the most part in India, agriculturists favored the customary strategy for product cutting by utilizing sickle, which takes a lot of time and a huge number of waged labors is required. So there is a requirement for the development of yield cutting machine which is profited for agriculturists as opposed to customary strategy and appropriate financially. In the wake of visiting different ranchers and their fields, it has been discovered that the agriculturists set forth some normal protests with respect to the collectors. These grumblings can be considered as imperatives while structuring the model. Harvest cutting machine is a mechanical gadget which is accustomed to cutting the dry cut stalks of grain break steam or covering of trunk tree.

In this way, by altering its strain it can without much of a stretch change slicing power starting with one harvest then onto the next. This can be pertinent for cutting of the harvest, for example, wheat, jawar, etc. Secondary selling study, there were a couple of issues that developed, for instance, how to extend the advantage, how to construct effective and how to diminish the cost. One of the basic activities in Wheat is gathering. On the wheat edit, a half percent of the hypothesis goes to a social event the yield and its transportation on account of increment in wages of the laborers and lesser openness of specialists inciting the intrigue of the work. Thus, with the plan to lessen the reliance on laborers in gathering, this task comes to take care of every one of these issues where the new development for apparatus in reaping will have the 
capacity to decrease the reliance on specialists. By utilizing the apparatuses like hardware, the reliance on the specialist can be decreased, profitability can be expanded, the expense can be lessened and the benefit can be expanded. The destinations of this venture were to make the audit about other research and study pertinence to the title, plan the model of mechanized shaper for reaping crop utilizing a few criteria, for example, it limits cost of collect, sets aside less opportunity to gather the yield, make collecting process less difficult and utilize shabby hardware and along these lines, select reasonable rule strategy for the manufacture and select the appropriate material, segments and parts for this new innovation. For the satisfaction of this point, it was chosen to pursue certain means which were Interviewing the neighborhood ranchers who had little scale arrive holding and enquire about the gathering rehearses and the products created and developing patterns in yield collecting, Interviewing farming gear makers to get data about different hardware that are accessible and are popular, Refer different global papers in little scale reapers delivered before lastly, structuring of collector.

\section{Methodology}

The technique is the precise, Theoretical investigation of the strategies connected to an examination or to the hypothetical examination of the strategy and standards related to part of the study.

\section{- Literature Review on Existing Machines \\ - $\quad$ Field surveying \\ - Writing audit \\ - Structure of yield shaper \\ - Cost estimation \\ - Manufacturing}

\section{Literature Review}

The author has studied in detail about agricultural ranch machinery and summarized in brief below. Physical work requires some serious energy and isn't viable as they can work for 3 to 4 hours at a stretch. Regardless of whether the landholding is little, it takes a multiday totally gathers the soybean trim. Additionally, the planting isn't finished with appropriate consideration. The machining center the task is to make a mix of reaping and gathering machine for the little scale agriculturists in India who have to arrive holding under two sections of land, to collect grain more efficiently. The dimension of motorization has been expanding consistently throughout the time of the joint endeavors made by the Government and the private division. Because of various projects actualized by the government of India throughout the years, the aggregate ranch control accessibility is assessed to have expanded from $0.295 \mathrm{kw} /$ ha in 1971 $72,1.72 \mathrm{kw} /$ ha in 2014-15.(1) .Uneven Landholding is the major challenges faced in Indian society. Despite the fact that the reception of ranch automation is expanding in India, it is generally locale explicit. Ranch motorization has low development rate in locales such a bumpy and messy land. The diminishing pattern in operational land holding is likewise perception the development of agrarian automation. Surprising expenses of machine and support, non-accessibility of fitting rural machines and gear that cook and suit the prerequisite of little-scale farmers, non-accessibility, and trouble in getting bank credit and little land holding are a portion of the variables that block homestead, automation and power ranchers to pursue the conventional methods for farming task. The utilization of ranch hardware is likewise reliant on framework and administrations accessible in the rustic zones. India keeps on being sustained by its negligible and little ranchers. Their holding (those underneath two hectares) considered for $84.97 \%$ of aggregate possessions in 2010-11 contrasted and $83.29 \%$ in 2005-06, the consolidated zone under these horde cultivated plots is $44.31 \%$ of the nation's aggregate cultivated region (it was $41.14 \%$ in the 20082009).The author has done a detailed field visit to know more about a rancher and its usage in rural areas.

On the basis of the collection of facts, the author has gathered the major challenges which farmers faces while using the agricultural machine.The structure depends on the necessity and interest for the smaller effective and moderate reaper. This interest could be seen just in collaboration with the ranchers of having land under 5 sections of land. The large portions of the landowners were from Wardha or nearby areas to Wardha. The principal objective of this study was to observe and gather information about collecting techniques which are being utilized by them; the issues are being confronted while utilizing these reaping strategies. Some of the major points raised by the farmers were ease of machine, machining cost, the procedures for collecting grains, the capacity of new machine and workability conditions.From these inquiries, we got the essential thought regarding the present circumstance of little-scale agriculturists. We likewise discovered that there is basic to have little scale reaper with every rancher for lessening there gathering cost.

Different methodologies have been proposed for enhancing motorized kind of product shaper in the horticulture field. Planning a collector machine to collect grains all the more effective. The research work concentrating on gathering task to the little landholder to cutting assortments of product in less time and with ease by considering the factor as power prerequisite, the simplicity of activity, field condition, time of activity and climatologically condition. Chavan has investigated the efficiency and benefit of the harvesting machine. He has also suggested major feedbacks from the field worker can help in solving the issue regarding the operational issue of these machines. Maruthi Prasad manufactured ultralow power sugarcane 
cutters which are very effective in cutting as well as gathering the sugarcane at a particular place. Adarsh Jain made machines for cutting pea crops. According to this study, the lower end of the arm is pendulum type dynamic analyzer which can cut the stalk at 900 to the stalk hub while blade speed is maintained from $2.28 \mathrm{~m} / \mathrm{s}$ to $7.23 \mathrm{~m} / \mathrm{s}$.

The cutting power is straightforwardly corresponding to cross-sectional zone. Atul Dange modified the structure of yield shaper. Fig. 1 shows the plan of the cutting edge. Sharp edge type was roundabout with the quantity of cutting eye into 42 pieces. Sharp edge material was carbide tip with edge size of $4 \mathrm{~mm}$ length, $3 \mathrm{~mm}$ width, and $2 \mathrm{~mm}$ stature. Pivot speed was rpm. Sharp edge width was $255 \mathrm{~mm}$. Cutting rate could be estimated as per requirement. Roundabout sort cutting edges are accessible in the market. This kind of sharp edge would encounter mileage on the shaper eye or the carbide tip, as appeared. At the season of cutting rice plants, which were in parallel slopes and ordinary space, a one of a kind propeller or motivation was required with the goal that three or much in excess of four rice slopes could be cut and flawlessly organized in a solitary stack. The lift was come about because of development of the cutting sharp edge with the cut snare, and a propeller to push the rice slopes that have been cut with the goal that the wheat slopes won't fall or crumple per slope that reason the wheat straw spill over.

The sponsor speed ought to not be too high or too low. In the event that the speed is too high, it causes the wheat slopes to tumble down or bowed yet not cut off since the wheat slopes have not been altogether cut off by the edge of the sharp edge, yet it has been driven by the machine. In the interim, if the speed is too low or moderate, the wheat slopes that have been cut already would crumble and can't be gathered with the following wheat slopes. In light of encounters, the estimation of propeller speed to cut four wheat slopes with a $25 \mathrm{~cm}$ plant dividing or proportional to a $100 \mathrm{~cm}$ working width of propeller drive began from the earliest starting point at the privilege part until the point that the left extended from 0.7 to 1 seconds.
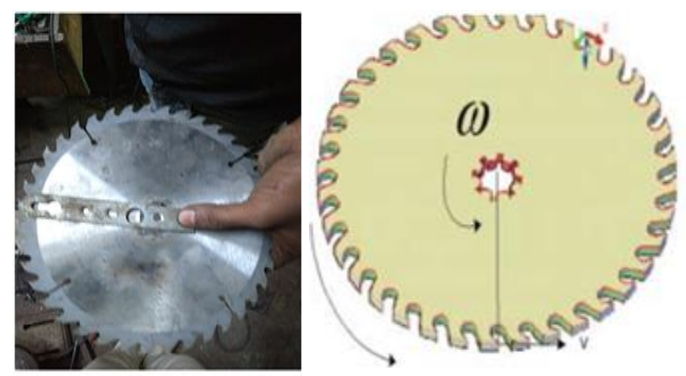

Fig. 1. Blade Cutter

The fabrication process is shown in the flow chart. The rough sketch can be seen in figure 3 .

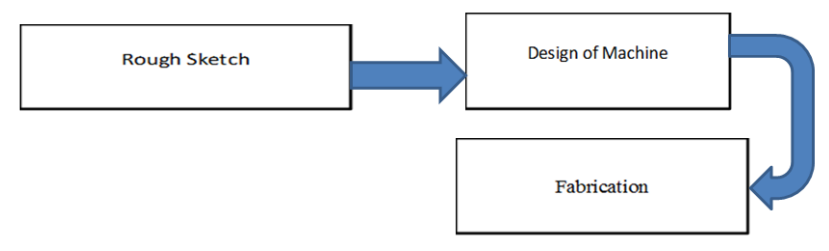

Fig. 2. Fabrication process

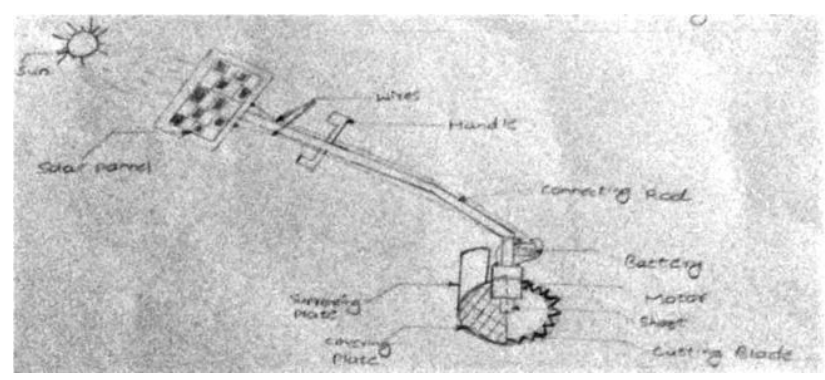

Fig. 3. Rough Sketch

In the planning stage, we have distinguished all the data and prerequisites, for example, equipment and programming and after that, we arranged about the task assets and necessities and Literature examines then Data was gathered from research papers, diaries and course readings. After that Market research and distinguishing proof of the required equipment programming was finished. Also finally Cost examination of all the required materials was finished. During the analysis phase, we did the investigation dependent on the execution and after that end distinguishing proof was finished. At that point limit, Limits were recognized dependent on condition conditions and most extreme load-bearing capacity of the machine.

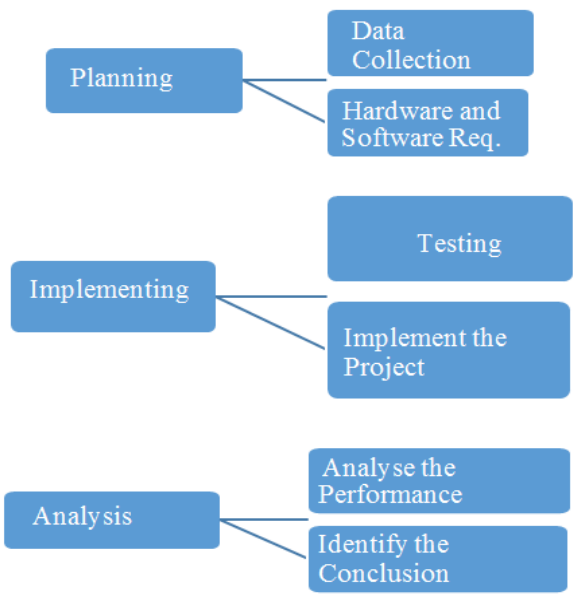

Fig. 4. Flow process

\section{Problem Definition}

Heater based mix throwing machine was seen which was overwhelming weight and caused a ton of vibration while blending of materials. To make the model ideal, an ideal material is should be chosen for cauldron, shaft, cutting edge and casing. This was 
accomplished through after system. Figure 5 demonstrates the selection of material criteria.

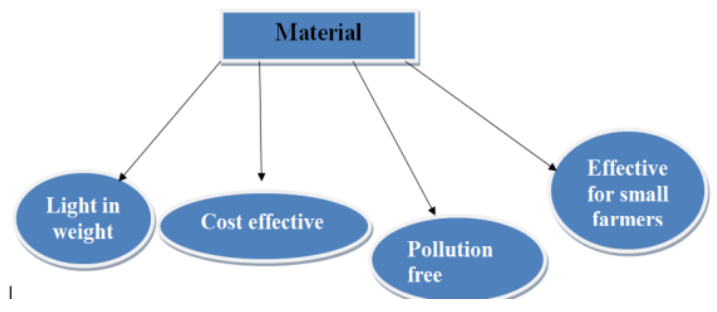

Fig. 5. Criteria of selection of material

\section{Material Selection}

The best possible determination of material for the diverse piece of a machine is the primary target in the creation of Machine. For a plan design, it is must be acquainted with the impacts, which the assembling procedure and warmth treatment have on the properties of materials. The decision of material for designing proposes relies on the accompanying elements:

- Availability of the material

- Suitability of material for the working condition in administration

- The expense of material

- Mechanical properties of the material

\section{Design Analysis}

It consists of a cast iron frame with the length of the frame $-60 \mathrm{inch}$, the width of the frame - 29inch and thickness of the frame- 1 inch. The material utilized for the development of the casing is press as it is solid, sturdy and shoddy and it just requires a layer of paint to shield it from rusting. Blade Material-Tungsten Carbide, Kerf - a cut made by cutting with a saw:2.0 $\mathrm{mm}$, Bore: $20 \mathrm{~mm}$. The solar panel is the next requirement for operating this machine to make it more eco-friendly and utilizing solar energy. The solar panel works on the principle of the photovoltaic effect. When two photons are absorbed at the same time the process called the photovoltaic effect. The photovoltaic effect is the creation of voltage or electric current in a material upon exposure to light and is a physical and chemical phenomenon. The electrons present in the valence band absorb energy and, being excited, jump to the conduction band and become free. The chemical bonds of the material are vital for the process to work, as crystallized atoms are ionized and create a chemical electric imbalance, driving the electrons. The standard and obvious photovoltaic effects are directly related to the photoelectric effect, though they are different processes. When the sunlight or any other light is incident upon a material surface These highly excited, non-thermal electrons diffuse, and some reach a junction where they are accelerated into a different material by a built-in potential (Galvani potential). This generates an electromotive force, and thus some of the light energy is converted into electric energy. Furthermore, a solar cell consists of charge collecting back and front electron, Semi-conductor in which electron-hole pairs are created by the absorption of incident solar radiation.

Now to rotate the blade there is a requirement of A.C/D.C motor. Hence one, $12 \mathrm{~V}$ D.C outfit motor that was chosen as they gave ideal rpm and torque while being light in weight and cheaper. It influences the blade to pivot at $3500 \mathrm{rpm}$. To move this machine from one place to another in the field a wheel is required to be attached to the machine. The wheels chose must be founded on the underlying plan and the general weight of the machine. The wheels we wound up picking were plastic wheels that were sufficiently able to help the heaviness of the gadget and had distance across that enabled the roller to keep up contact with the shaft. There are two batteries that have been utilized in this project to maintain the required capacity to various segments. The greater battery that is two, $12 \mathrm{~V}, 7 \mathrm{~A}$, has been utilized for giving capacity to the wiper engine, each of the four D.C motor and blade. The battery purchased is manufactured by Luminous and was picked as it is adequate to give capacity to a time of around 4 hours. The little battery is additionally $12 \mathrm{~V}, 1$ $A$, its motivation is to give capacity to the various components.

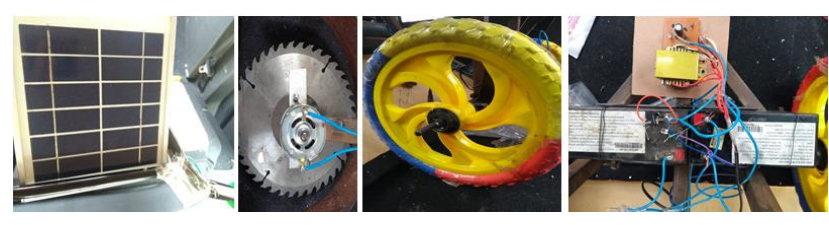

Fig. 6. Different components

\section{Assembling of All Different Components}

The Solar Powered wheat Crop Cutter comprise of a base casing, supporting edge, DC engine, sun-oriented board, switch, electric wiring, battery, haggles edges. These parts are mounted on an edge, alongside wheels are fitted to this casing.
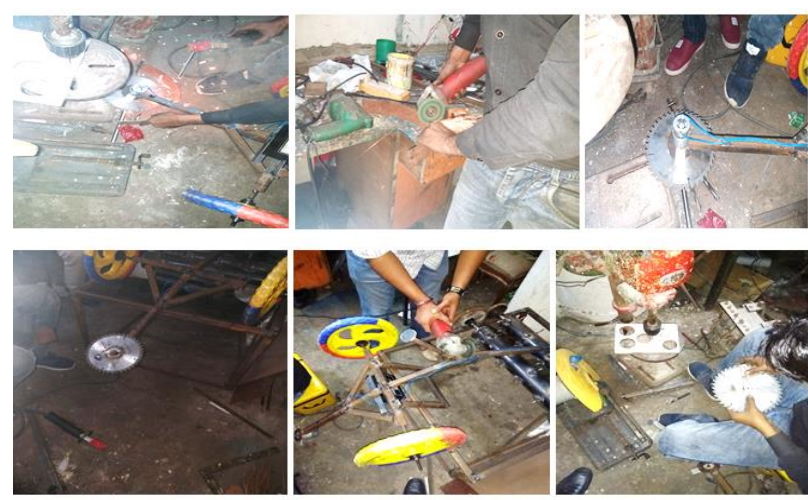

Fig. 7. Assembling of different components 
The development of this collector is finished by pushing i.e. by utilizing human fuelled. This product shaper is profoundly proficient as it takes a shot at sun oriented controlled and it is reasonable to little agriculturists because of its basic working. The preferred standpoint is it doesn't require any upkeep, simple to deal with and it can cut diverse products with the assistance of straightforward stature modification by nut and screw component. Working of the product shaper happens stepwise

Going to the working of Solar Powered Hand Held Crop Cutter, it has boards mounted in a specific course of action at an edge of 45 degrees so that it can get sunlight based radiations with high force effectively from the sun. These sun-powered boards convert sunlight based vitality into electrical vitality. Presently this electrical vitality is put away in batteries by utilizing sun-powered chargers. The primary capacity of sun oriented charger is to build the current from the boards while batteries are charging, it additionally separates the sun based boards from the batteries when they are completely charged and furthermore interfaces the board when the charging in the battery is low. The motor is associated with the batteries through interfacing wires. Between these two mechanical circuits breaker switch is given. It begins and quits working of the motor. From this motor, the power transmits to the instrument and this makes the cutting edge to slide on the settled sharp edges and this makes to cut the product. We are utilizing the DC motor which takes a shot at key changing over electrical vitality into mechanical work. As the shaper will turn it will cut the product consistently, this will cause wearing and tearing of shaper. The two wheels help to move the machine starting with one place then onto the next. We will utilize metal casing case, essentially it will build the life of the machine. One shaper will decrease 7 to 8 work works which at last increment the productivity. In this manner, it will expand the productivity and also monetary development of rancher in the one-time venture of the machine cost.

Table 1 Budget of project

\begin{tabular}{|c|c|}
\hline Part Name & Cost(INR) \\
\hline Cast Iron Frame & 1500 \\
\hline Two Wheels & 400 \\
\hline Handle of the frame (cycle handle used) & 375 \\
\hline Motor & 550 \\
\hline wirings & 400 \\
\hline Two Battery & 1000 \\
\hline Charger system & 275 \\
\hline Solar panel & 400 \\
\hline Electrical works outside & 800 \\
\hline Switch & 30 \\
\hline Bearings (2) & 100 \\
\hline Total & $\mathbf{5 8 3 0}$ \\
\hline
\end{tabular}

The aggregate last expense of our venture came to be around Rs.6000 (approx.) Consequently, we reason that the sunlight based solar panel wheat cutting machine made by us is very expense effective and proficient and alongside this, it is additionally simple and easy to work since it tends to be controlled with a basic portable application by anybody and from anyplace.

\section{Conclusion}

The fundamental goal was to make straightforward, minimized, effective and ease little scale food grains for small to medium size landholders. These machines satisfied all goals and the following outcomes were drawn on based of work:

1) Based on collections of data's from onsite farmers, all the requirements can be fulfilled by this harvesting machine.

2) The machine was operated in the field, initial trials suggest it can work effectively and can meet the demand of farmers.

3) The main challenges faced during the operation were controlling the cutter speed, which can be controlled by the help of more sophisticated electronic controlled devices.

4) This has advantages over the existing machine as its price is lower and can easily be transported from one place to another.

5) It has reduced size and can be operated with the help of renewable sources of energy, i.e thermal energy.

6) Overall this machine is eco-friendly, can be helpful to low earning farmers for their ease of living and increase their productive work to increase their earnings.

\section{References}

Laukik P. Raut, Vishal Dhandare, Pratik Jain, Vinit Ghike, Vineet Mishra (2014), "Plan, Development, and Fabrication of a Compact Harvester", International Journal for Scientific Research and Development| Vol. 2, Issue 10

The government of India, "Indian rural insights 2015-16", Ministry of Agriculture and Farmers Welfare, Department of Agriculture, Cooperation and Farmers Welfare, Directorate of Economics and Statistics, New Delhi

Christopher Boyle, Ian Jutras, Christopher Molica, Earl Ziegler R. (April 28, 2012 ), " Designing a Small-Scale Grain Harvester: A Tool for Urban and Peri-urban Growers"

Aravind C., Shivashankar V., Vikas R., Vikas V. (2015), " Design and Development of Mini Paddy Harvester", International Journal for Scientific Research and Development, Vol. 3, Issue 05, 2015

Nesar Mohammadi Baneh, Hosein Navid and Mohammed Reza Alizadeh (2012) "Structure and improvement of a cutting head for versatile gatherer utilized in reaping tasks" Journal of natural sciences 6(3): 69-75

Farm control sources, their accessibility, and future necessities to support farming generation, by N. S. L. Srivast.

The relationship between Stalk Shear Strength and Morphological Traits of Stalk Crops, by Li Liang and Yuming Guo.ava. 


\section{Appendix}

Maximum rpm of cutter $=7000$

Cutter blade rpm $=3500$

Length of frame $=60 \mathrm{inch}$

Width of frame $=29 \mathrm{inch}$

Thickness of frame $=1$ inch

Solar panel dimension $=7 * 7$ inch

Weight of the model $=7 \mathrm{~kg}$

Radius of blade $=190 \mathrm{~mm}$

Bore diameter $=5 \mathrm{~mm}$

Voltage of battery $=24 \mathrm{~V}$

Current supply = 14 ampere
Velocity of blade cutter $(40$ teeth $)=$

$=\mathrm{r} * \mathrm{w}$

$=[\mathrm{r} * 2 * 3.14 * \mathrm{~N}] / 60$

$=[0.019 * 2 * 3.14 * 3500] / 60$

$=4.9 \mathrm{~m} / \mathrm{s}$

Required power to run a small scale harvester $=$

$=[$ weight $*$ velocity $*$ gravity $] / 1000$

$=(7 * 4.9 * 9.81) / 1000$

$=336.48$ watt

Power rating (Actual power) $=$

$=\mathrm{V} * \mathrm{I}$

$=24 * 14$

$=336 \mathrm{~W}$ 